\title{
A Configuração da Disciplina Escolar Matemática: Professores do Atheneu Sergipense*
}

\author{
Eva Maria Siqueira Alves
}

\begin{abstract}
Resumo
Desde os primeiros momentos de organização dos estudos secundários em Sergipe, há a presença das Matemáticas. Porém, cabe indagar: quem foram os professores responsáveis por ministrar essas aulas? Esse artigo investiga a história da disciplina escolar - Matemática no Atheneu Sergipense, tomando como eixo central e que transforma as finalidades em ensino, a pessoa do docente, determinante na configuração daquele saber nos estudos secundários, no período do final do século XIX e início do XX. As fontes analisadas são documentos produzidos por aquela Casa de Educação Literária, arquivados no Centro de Educação e Memória do Atheneu Sergipense, além das peças legislativas que possibilitam inferir sobre a história dos sujeitos ministrantes das aulas das Matemáticas.
\end{abstract}

Palavras-chave: História das Disciplinas; Atheneu Sergipense; Matemática.

\section{The configuration of the school discipline mathematics: Atheneu sergipense's teachers}

\begin{abstract}
There has been the presence of "Mathematics" ever since the first moments of the organization of the secondary studies in Sergipe. However, it is suitable to ask: who were the teachers responsible for giving those classes? This article investigates the history of the school discipline - Mathematics at Atheneu Sergipense -, taking as its core issue, and that which transforms purposes into teaching, the teacher as a person himself, a determinant in the configuration of that knowledge in the secondary studies during the end of the XIX and beginning of the XX centuries. The sources analyzed are documents produced by that House of Literary Education found in the archive of the Center of Education and Memory of Atheneu Sergipense, as well as legislative briefs which enable us to make inferences about the history of those involved in giving Mathematics classes.
\end{abstract}

Keywords: History of Disciplines; Atheneu Sergipense; Mathematics.

* Este artigo apresenta os resultados da pesquisa "Professores das Matemáticas do Atheneu Sergipense (18701931)", financiada pela Fundação de Apoio à Pesquisa e à Inovação Tecnológica do Estado de Sergipe - FAPITEC, Edital 03/2007, desenvolvida no ano de 2008 e, tendo como bolsista de Iniciação Científica, a graduanda em História da UFS, Iara Alves de Farias. 


\section{Introdução}

Compreender a configuração do saber matemático na escola secundária sergipana foi o interesse inicial das investigações, tendo em vista ser essa a área de minha formação. No entanto, para uma pesquisa em história da educação, tal argumento é frágil e insuficiente. Necessário seria amparar a justificativa em elementos inerentes à própria disciplina, objeto da pesquisa.

Elementos estruturantes de uma disciplina escolar como sua gênese, finalidades, conteúdos ministrados, têm suscitado pesquisas por mim desenvolvidas e orientadas, como nos casos das disciplinas de Química, Sociologia, Religião, Desenho, Português, História, Matemática, que realçam as práticas na instituição Atheneu Sergipense, compreendendo a escola como lugar de produção, investigando a cultura escolar, por meio da história das disciplinas.

Examinando os Planos de Estudos do Atheneu Sergipense, foi possível afirmar, por meio das evidências da documentação, a presença das Matemáticas, desde os primeiros momentos de organização dos estudos secundários em Sergipe. Se não com tal terminologia, ao menos com rubricas específicas de seus ramos, como a cadeira de Geometria, ministrada no Liceu de São Cristóvão, em 1833; a de Aritmética, Geometria e Trigonometria, lida no Liceu de São Cristóvão, no período de 1848 a 1855; a de Álgebra, Geometria e Trigonometria no Liceu Sergipense, em 1862; a de Aritmética, Álgebra e Geometria, no Atheneu Sergipense, em 1870; a de Matemática Elementar, também no Atheneu Sergipense, em 1905; e, finalmente, a de Matemática, no Atheneu Pedro II, em 1931.

Esse artigo investiga a história da disciplina escolar - Matemática no Atheneu Sergipense, tomando como eixo central e que transforma as finalidades em ensino, a figura do docente, indagando: quem foram os professores responsáveis pelas cadeiras das Matemáticas no Atheneu Sergipense? Que tipo de formação possuíam? Como se tornaram professores daquela instituição? Ministravam aulas somente no Atheneu Sergipense? Que outras funções desempenhavam na sociedade?

Guiada por tais questões, tomo como fontes privilegiadas para análise os documentos produzidos por aquela "Casa de Educação Literária" (ALVES, 2005) e arquivadas no Centro de Educação e Memória do Atheneu Sergipense - CEMAS ${ }^{1}$, além de peças legislativas, notícias da imprensa, de modo a inferir sobre a história dos agentes que participaram da configuração do saber matemático na escola secundária, revelando práticas de uma disciplina escolar e da instituição Atheneu Sergipense, elementos constituintes da História das Disciplinas com suas contribuições para a História da Educação.

\section{O Atheneu Sergipense}

Lendo os documentos e dialogando com as fontes, encontramos e reconhecemos o Atheneu Sergipense como uma instituição que projetou, no panorama político e social, inúmeros vultos que prestaram benefícios incalculáveis em todas as profissões e atividades que desempenharam.

Os sujeitos que por lá passaram, alunos, professores, diretores, funcionários técnicos e administrativos, contribuíram de forma a projetar aquela Casa de Educação Literária em parte significativa da memória de Sergipe. Então vejamos.

Criado em 24 de outubro de 1870, com os cursos de Humanidades e Normal, o Atheneu Sergipense tentou manter-se fiel aos seus principais objetivos: ministrar uma instrução secundária, de caráter literário e científico, necessária e suficiente de modo a

\footnotetext{
1 O Centro de Educação e Memória do Atheneu Sergipense - CEMAS - tem por meta preservar a documentação existente, a fim de manter viva a memória daquela instituição que é parte significativa da memória do estado de Sergipe. O projeto, sob a minha coordenação e a participação de alunos de Iniciação Científica Júnior, amparados financeiramente pela FAPITEC, foi desenvolvido no período de 2005 a 2007. Prosseguindo os trabalhos, foi aprovado pelo Edital 01/2008/ PROEXT/MEC/CULTURA o projeto do CEMAS, objetivando salvaguardar o patrimônio cultural.
} 
proporcionar à mocidade subsídios para matricularse nos cursos superiores, como também para desempenhar variadas funções na sociedade.

Coube ao Governo prover as cadeiras, quando da criação do Atheneu Sergipense, elegendo "as pessoas que mais aptas lhe pareçam para o fim que se pretende" (Regulamento Orgânico da Instrução Pública da Província de Sergipe, 24 de outubro de 1870, art. 23). Com esse entendimento, foram selecionados, para as devidas cadeiras, lentes que traziam em suas vidas anteriores experiências de magistério, conhecidos e respeitados pela sociedade. Nesse tipo de seleção, deve ter havido a imposição do poder, uma vez que, para o primeiro quadro de docentes do Atheneu Sergipense, não houve concurso, e os "mais aptos" foram indicados. ${ }^{2}$

As demais cadeiras e vagas que surgissem posteriormente apenas poderiam ser preenchidas por concurso público. Os rituais, métodos, personagens, papéis e formas de julgamento são matérias detalhadas nas legislações e demais documentações que regulamentam as provas de defesa de tese de livre escolha ou sobre assunto sorteado, as provas práticas, quando a natureza da cadeira exigia, as provas escritas, orais e as argüições.

Concebido por Goodson (1998) como artefato social, o currículo escolar tem propósitos humanos deliberados. Nessa direção, pode-se investigar qual o propósito e a finalidade da criação do Atheneu Sergipense e com ele, naturalmente seus Planos de Estudos, que contou inicialmente com as seguintes cadeiras: Gramática Filosófica da Língua Nacional e Análise dos Clássicos; Retórica e Poética; Gramática e Tradução da Língua Latina; Gramática e Tradução da Língua Francesa; Gramática e Tradução da Língua Inglesa; História e Geografia; Filosofia Racional e Moral; Pedagogia; Aritmética, Álgebra, Geometria.

Os conteúdos de ensino disponibilizados no Atheneu Sergipense naquele momento integram-se com os objetivos impostos pela sociedade, aqueles ne- cessários aos Exames de Preparatórios do século XIX e início do século XX, estando nesse meio as Matemáticas. É como declara Chervel (1990): “os conteúdos de ensino são impostos como tais à escola pela sociedade que a rodeia e pela cultura na qual ela se banha” (CHERVEL, 1990, p.180). É a transformação do público escolar que impulsiona adaptações às disciplinas.

E dentre essas adaptações encontram-se as Matemáticas, requisito para a educação, ampliando os conhecimentos necessários àqueles que no Atheneu Sergipense buscavam formação intelectual e cultural.

O primeiro requisito da educação moderna, como base de reorganização social, é a universalidade de conhecimentos.

O homem cientificamente preparado deve conhecer, ao menos elementarmente, as mathematicas, a physico-khimica, a biophysiologia, a psykhologia-moral. Deve ter boas noções de arithmetica, de algebra, de geometria, de mekhanica, de cosmologia, de astronomia sideral e planetaria, de geodesia, de geographia physica, de geologia, de mineralogia, de paleontologia, de botanica, de zoologia, de anatomia, de histologia, de pathologia, de psyhologia, de moral, de anthropologia, de ethnologia, de linguistica, de historia e geographia-historia, de industria, de arte, de litteratura, de sociologia, de legislação, de politica.

E mais, deve ter estudos classico solidos (JÚLIO RIBEIRO, 1908. In: MORSE, 1970, p.212).

As ciências deveriam, pois, compor o conjunto dos saberes estudados para a formação do "homem cientificamente preparado". No período em que foi criado o Atheneu Sergipense, a ênfase estava voltada para as Humanidades, além dos conteúdos das Matemáticas.

\footnotetext{
2 As fontes investigadas indicam que o professor de Gramática e Tradução da Língua Inglesa, Doutor em Ciências Sociais na Faculdade de Córdova - Argentina, Justiniano de Melo e Souza, prestou concurso para ingressar no Atheneu Sergipense.
} 
Esta investigação pauta-se sobre a perspectiva da figura do agente professor das Matemáticas, é o profissional que, sem prestar concurso ou por seleção submetido, passa a integrar o quadro docente daquela Casa de Educação Literária, agindo em sala de aula na construção do saber Matemático. São eles que participam da renovação de uma disciplina com os objetivos a alcançar e a população a instruir, como também da "cultura e da vida social de seu tempo" (CHERVEL, 1990, p.198).

\section{A Disciplina Escolar Matemática e seus Professores}

O conceito aqui admitido de disciplina escolar é o posto pelo autor André Chervel (1990). Este afirma que uma disciplina é "em qualquer campo que se a encontre, um modo de disciplinar o espírito, quer dizer de lhe dar os métodos, e as regras para abordar os diferentes domínios do pensamento, do conhecimento e da arte" (CHERVEL, 1990, p.180). Alerta o autor para a presença marcante da figura do professor: "No coração do processo que transforma as finalidades em ensino, há a pessoa do docente" (CHERVEL, 1990, p.191). São esses professores que transmitem ideários da sociedade em que vivem.

Compactuando ainda com Chervel (1990), entendo que o objetivo das pesquisas no campo da história das disciplinas escolares coloca para o pesquisador investigar três elementos: a gênese, a finalidade e o funcionamento. Aqui o foco é a figura do docente relacionado - tanto a gênese, que se refere aos primeiros professores desse saber no Atheneu Sergipense; como as finalidades da cadeira e o funcionamento da mesma, vista pela formação dos professores.

Uma das documentações analisadas nos estudos da história das disciplinas, nesse caso, das Matemáticas no ensino secundário em Sergipe relacionada ao docente, é relativa à série dos textos produzidos pela instituição. O trecho que segue, extraído de um relatório, defende a presença de mais de um professor das Matemáticas, desde os tempos do Liceu de São Cristóvão:

Seria, Snrs, de grande vantagem, que houvesse n'este Lyceu, como no da Bahia, dous lentes de Mathematicas, encarregan- do-se um de lecionar Arithmetica, $e$ Algebra, e outro Geometria, e Trigonometria, visto que foi alli tomada esta deliberação por se ter justamente reconhecido como insuficientes as noções, que outrora bebião os estudantes de um só lente, e em um anno nestas materias todas: e assim os estudantes d'este Lyceu, que alli se apresentaram para serem examinados, terão de ser julgados com razão mais fracos do que os d'essa Provincia, por terem de afogadilho ouvido as numerosas lições, que o seo Professor se vê forçado a lhes dar na metade do tempo em que as dá que alguns d'aquelles (Relatório da Congregação do Liceu de Sergipe, enviado a Assembléia Provincial, em 18 de maio de 1848, Livro de Correspondências do Liceu de São Cristóvão).

No entanto, essa defesa só é aceita e fixada na legislação que determinava dever ter o Atheneu Sergipense dois lentes de "Mathematicas Elementares, sendo um para Arthmetica e Algebra, outro para Geometria e Trigonometria”, no ano de 1899 (Cf. Art. 4, Decreto 351, de 9 de junho de 1899).

Na documentação analisada do Liceu de São Cristóvão, explicita-se a necessidade de mais de um lente para as Matemáticas, mas também expõem a presença daqueles que lecionaram as Matemáticas em Sergipe: a cadeira de Geometria foi provida em 20 de outubro de 1832 pelo Frei José dos Prazeres Bulhões, também Diretor do Liceu de São Cristóvão; Galdino Barbosa de Araújo foi lente da cadeira de Aritmética, Geometria e Trigonometria do Liceu de Sergipe nos anos de 1847 a 1855; além de Sebastião José Basílio Pirro, que foi substituto da cadeira de Geometria no Liceu de São Cristóvão, no ano de 1850 (Cf. Livro de Correspondências do Lyceu de São Cristóvão).

Muito embora a legislação exigisse prova escrita para prover as cadeiras do Atheneu Sergipense, no concurso de Aritmética e Geometria, com a "solução ou demonstração de qualquer problema ou theorema", e para a oral "qualquer parte da mesma sciencia" (Art.99, Regulamento Orgânico da Instrução Públi- 
ca, 1870), o provimento das primeiras cadeiras do Atheneu Sergipense não foi feito por meio de concursos, mas por escolha do Governo.

Depreende-se assim que a finalidade das disciplinas inscritas nos textos oficiais nem sempre de fato coincide com a realidade. Cabe, portanto, ao historiador das disciplinas, distingui-los da história das políticas educacionais (CHERVEL, 1990). Necessário se faz examinar a literatura abundante produzida na instituição, tais como: relatórios, atas, teses apresentadas, utilizando assim a dupla documentação "dos objetivos fixados e da realidade pedagógica" (CHERVEL, 1990, p. 191).

Desta forma, analisando os diferentes textos produzidos pelo Atheneu Sergipense, localiza-se o senhor Tito Augusto Souto de Andrade indicado para a cadeira de Aritmética, Álgebra e Geometria, no ano de 1870.

Tito Augusto iniciou suas atividades de magistério como professor de primeiras letras em Laranjeiras - SE. Na mesma cidade, por concurso, lecionou as cadeiras de Filosofia, Geografia e História no Internato lá existente. Suspensas estas aulas, foi transferido para as cadeiras de Francês e Geometria em Aracaju, em 1868. Quando D. Pedro II veio a Sergipe, em 1860, assim se expressou o ilustre visitante em seu Diário:

Aula de filosofia e geografia de Tito Augusto Souto de Arquimedes (sic) [Andrade], 4 de filosofia e 4 de geografia; 2 presentes de que um de ambas e o outro de geografia sòmente. Respondem sofrivel sôbre filosofia, idem sôbre geografia. Não parecendo o professor não ter idéias muito exata sôbre a parte astronômica (Diário do Imperador, 1965, p.72).

Mesmo recebendo crítica do Imperador Dom Pedro II, Tito Augusto integra o corpo docente do Atheneu Sergipense por longo período. De forma atuante, demonstra indignação quanto ao primeiro Estatuto do Atheneu Sergipense, elaborado pelos membros de sua Congregação, ao trazer a indicação dos compêndios a serem adotados para as aulas de Aritmética, Álgebra e Geometria: os de Cristiano Benedito Ottoni.
Logo na primeira reunião da Congregação em que participou, (30/03/1871), o professor da cadeira, Tito Augusto Souto de Andrade, foi contrário às determinações impostas. Requereu a reformulação do Estatuto do Atheneu Sergipense, visto que, na ocasião de sua confecção, não estavam presentes mais de quatro professores, de um total de oito, não sendo eles ouvidos a respeito. Dizia ainda não estar de acordo com os compêndios adotados para sua cadeira, pois não o haviam consultado para tal determinação.

Apesar do protesto do professor, pois desejava organizar sua disciplina indicando a obra a ser utilizada, os compêndios permaneceram até o ano de 1874, quando passaram a ser adotados os de Macedo Costa e Bernardo Carneiro, em 1888 (ALVES, 2005).

Um artigo publicado na imprensa local argumentava ser de acordo com a divisão das cadeiras das Matemáticas (Aritmética, Álgebra, Geometria), assim como as de Geografia e História, por razões que pareciam óbvias para o autor do texto.

\section{[...] materias complexas e amplisseimas} [sic], em um anno, quer umas quer outras, são invenciveis, doutrinadas por um mesmo professor, que ou se occupará exclusivamente de um dos ramos das sciencias, objeto de sua cadeira, deixando incompleto o respectivo curso, ou passará por todos elles de um modo imperfeito $e$ sem proveito procurado na respectiva instituição (Jornal de Aracaju, 14 de janeiro de 1874, sem identificação de autoria).

As fontes afirmam que os professores preocupavamse em desenvolver os estudos de forma prática, concreta, mas também de forma científica, além de demonstrarem ações para organizar a disciplina. É a fala do próprio agente, é o "auto interesse dos professores em suas vidas laborais" (GOODSON, 1990, p. 252).

Manuel Luiz Azevedo d'Araujo, Diretor do Atheneu Sergipense, preocupando-se com o andamento dos estudos lá realizados, defendia também a divisão das cadeiras, como medida essencial para uma melhor aprendizagem dos alunos. Parecer semelhante tinha o Presidente da Província, Antonio dos Passos 
Miranda, em seu relatório de março de 1874. Declarava, referindo-se à divisão das cadeiras:

\begin{abstract}
A divisão que proponho, evita o atropelamento do ensino dessas matérias, que transmittido promiscuamente e no pouco tempo assignado ás respectivas aulas, não pode ser completo e satisfactorio para os exames.

Creadas essas cadeiras, podem as de geometria e historia ser postas a concurso e a de rethorica apenas provida por nomeação interina, conferida a pessoa de reconhecidas habilidades e mediante a gratificação rasoavel, até que o numero de alumnos demonstrem a carencia de um maior sacrificio da parte da província.
\end{abstract}

O projeto apresentado à Assembléia Legislativa de Sergipe, em 8 de abril de 1874, tem a seguinte redação:

Art. $3^{\circ}$. O Presidente da Provincia melhorará e completará o serviço da instrucção secundaria dada no Atheneu Sergipense, dividirá a cadeira de geometria da de arithmetica é álgebra, a cadeira de historia da de geographia, a de religião da de pedagogia e poderá crear a de rhetorica $e$ poética.

No entanto, pela Resolução 968, de 21 de abril de 1874, Antonio dos Passos Miranda decretava:

\section{Art. $3^{\circ}$. O presidente da provincia poderá quando ache conveniente dividir a cadei- ra de historia da de geographia, a de geo- metria da de arithmetica e a de religião da de pedagogia, podendo igualmente crear a de rhetorica e poética.}

O projeto de lei revelava certeza pelo verbo empregado-dividirá; por conseguinte, a Lei colocou "quando ache conveniente". No entanto, nesse mesmo ano, 1874, foram determinados horários para as aulas de
Aritmética e Álgebra das $7 \mathrm{~h}$ às $8 \mathrm{~h}$ 30min; Geometria das $2 \mathrm{~h}$ às $3 \mathrm{~h} 30 \mathrm{~min}$. Dessa forma, o elemento tempo subsidia inferir que as cadeiras foram divididas, mesmo porque tais evidências encontram-se nas Atas da Congregação do Atheneu Sergipense, incluindo os nomes dos respectivos lentes a ministrá-las. No Regulamento de 20 de abril de 1875, tal divisão torna-se explícita. Assim ficaram as cadeiras: Geometria, compreendendo o Desenho Linear; Aritmética, Álgebra e suas aplicações mais gerais.

Aberta para concurso a cadeira de Geometria no ano de 1875, foi indicada como mesa examinadora os seguintes professores: Sancho de Barros Pimentel (lente de Filosofia Racional e Moral), Tito Augusto Souto de Andrade (lente de Aritmética, Álgebra e Geometria) e Brício Cardoso (lente de Retórica e Poética). O professor Barros Pimentel, não se considerando apto para examinar os candidatos, encaminhou por ofício, ao Diretor da Instrução Pública e também Diretor do Atheneu Sergipense, o Doutor Thomaz Diogo Leopoldo, sua recusa, alegando a impossibilidade de participar como membro examinador de Geometria "por não julgar-se possuidor dos conhecimentos precisos para examinar naquella sciencia, por quanto apenas tinha aprendido-a como preparatorio" (ATA DA CONGREGAÇÃO, 27 de agosto de 1875). Assim, Antonio Diniz Barreto (lente de Latim) assumiu a função de examinador naquele concurso.

Depreende-se que, ao estabelecer as mesas examinadoras, estas estiveram compostas de profissionais, não só da área específica do concurso em questão, mas também de outros membros do quadro docente da instituição, podendo, segundo a legislação, ter também membros externos à escola. Isso é observado em diferentes concursos examinados, cabendo a cada um dos docentes, julgando suas capacidades, aceitarem ou não participar das mesas.

Naquele concurso, esteve inscrito o candidato Pedro Pereira de Andrada, que tirando à sorte o ponto para a prova escrita de Geometria, teve o tempo de duas horas para a realização da mesma. "Minuciosamente examinada", a comissão atribuiu a qualificação de "optima". Em seguida, examinado o ponto da prova oral, o candidato foi julgado com igual qualificação. Após o que, como regia o Regulamento, os exa- 
minadores, por escrutínio secreto, procederam ao julgamento final, aprovando com distinção, para compor o corpo docente do Atheneu Sergipense, o engenheiro Pedro Pereira de Andrade. Em suas crônicas sobre a passagem do século em Sergipe, Edilberto Campos recorda que o engenheiro era bastante conhecido em Aracaju:

Encontrei pessoalmente o Dr. Andrade já velhinho ensinando geometria no Ateneu Sergipense que eu freqüentava, em 1898, sem ser nêle matriculado, porque estudava matemática particularmente com o prof. Teixeira de Faria. Eram companheiros Genulfo Freire da Fonseca, Antonio Casais, entre outros. Genulfo, inteligente porém vadio, roletou a canivete a flecha com que o professor apontava as figuras desenhadas no quadro-negro e em dado momento a dita se partiu... O velho ficou furiosos e perguntou: Quem foi o moleque que fêz isso? Ninguém se apresentou. Talvez suspeitando do Genulfo, mandouo à pedra: Trace uma reta horizontal AB.... (fazia questão que fossem estas as letras). Enunciou um teorema e ordenou: Demonstre isso.... Genulfo pensou, pensou, e disse: Vou de uma reta $A B$ fazer uma circunferência CD.... Ah! Seu vadio, você não vai fazer nada!... E dirigindo-se a mim: - Venha o senhor à pedra. - Prof. Eu não posso; não estou matriculado no Ateneu... Então o que está fazendo aqui? Vá-se embora! E fui mesmo para nunca mais voltar (CAMPOS, 1968, p. 96).

São as ações e o poder do professor no processo de análise de uma disciplina escolar. É o cronista fotografando a prática na sala de aula, considerando a dupla documentação, a dos objetivos fixados e da realidade pedagógica.

Francisco Teixeira de Faria, professor particular do cronista, nasceu a 14 de julho de 1860, em Itabaiana - SE, estudou no Atheneu Sergipense e concluiu, em 1884, na Bahia, o curso de Farmácia. Foi professor concursado das cadeiras de Latim e Francês em Estância - SE, sendo depois nomeado lente de Matemática da Escola Normal, regendo também a cadeira de Geometria e Trigonometria no Atheneu Sergipense, no período de 1893 a 1915. Foi Diretor interino da Instrução Pública do Estado de Sergipe, falecendo a 25 de abril de 1923.

Ao analisar o jornal O Necydalus, Vidal (2009) refere-se a um concurso realizado pelos alunos do Atheneu Sergipense para eleger, com argumentação, qual a mais bela, simpática e agradável das disciplinas lá ministradas. A esse respeito, o aluno, identificado como G.M.M., justifica sua opção pela Matemática, por ser essa a matéria que estudava com maior gosto, e sua escolha se deu em razão do professor, de "suas maneiras dedicadas, rectas e serias, e seu modo de ensinar" (VIDAL, 2009, p.141). Tais características se referem ao professor Francisco Teixeira de Faria. Ainda nesse mesmo concurso, não se escondendo em inicias, o estudante Matias Fontes Dantas declara seu voto também à ciência Matemática:

Prefiro perder todos os amigos a renegar um ideal.

Convidado por alguns collegas para aqui gravar meu voto, tenho que satisfazer o convite, para mim honroso.

Sei que não disponho do cultivo necessário para isto, como meus collegas que aqui já figuraram, porém, tacteando, procurarei gravar aqui em poucas e francas palavras e resumidas figuras, o meu voto. Indeciso não estou, - voto na Mathematica (O Necydalus, In: VIDAL, 2009, p.142).

Mesmo se submetendo a concurso para uma determinada cadeira, era lícito que os professores do Atheneu Sergipense migrassem para outras disciplinas por diferentes motivos, mas amparados pelo regulamento que admitia permutar entre si as respectivas cadeiras, ou transferir-se para as cadeiras vagas, mediante requerimento ao Governo e parecer da Diretoria. Os professores substituíam seus colegas nas cadeiras vagas decorrentes de pedidos de licença (são muitos os pedidos de licença por motivo de saúde) ou pela neces- 
sidade de substituir colegas quando saíam para outras funções fora do Atheneu, em diferentes circuitos culturais. Observa Chervel: "A taxa de renovação do corpo docente é então um fator determinante na evolução da disciplina" (CHERVEL, 1990, p. 197). É a polivalência dos professores do ensino secundário também constatado no Atheneu Sergipense.

É razoável dizer daquele momento como um grupo de profissionais construindo socialmente a disciplina escolar Matemática. Os professores do Atheneu Sergipense buscaram criar um ambiente estimulador para os estudos secundários, mesmo não sendo formados com essa finalidade, mas dedicavam-se a estudar e transmitir conhecimentos àqueles jovens que desejavam seguir seus estudos nas academias superiores. A história desses sujeitos ministrantes das aulas das matemáticas, sua formação, sua carreira profissional, os saberes requeridos para ser professor, a seleção para ingresso, são aspectos fundamentais da cultura, que possibilitam a compreensão da configuração das disciplinas escolares. Nesse sentido, declara Nóvoa:

\section{A profissionalização não é um processo que se produz de modo endógeno. Assim, a his- tória da profissão docente é indissociável do lugar que seus membros ocupam nas relações de produção e do papel que eles jogam na manutenção da ordem social. Os docentes não vão somente responder a uma necessidade social de educação, mas tam- bém criá-la (NÓVOA, 1991, p.16).}

As análises documentais apontam o farmacêutico, bacharel, promotor, juiz e deputado, Joaquim do Prado Sampaio Leite, para compor o quadro docente do Atheneu Sergipense. Ele esteve à frente das disciplinas Aritmética e Álgebra, em 1882, lecionando também em outros períodos as disciplinas de Literatura, Lógica, Psicologia, Direito Político.

Outros foram os professores das Matemáticas no Atheneu Sergipense. Eutychio de Novaes Lins, natu- ral de Lagarto - SE (30 de maio de 1825), concluiu o curso Normal em 1874, estabeleceu-se por um tempo na Bahia e, ao retornar a Sergipe, foi nomeado Tabelião na cidade de Estância. Retornou ao magistério como professor interino de Aritmética e Álgebra, em 1904, no Atheneu Sergipense, sendo nomeado, no ano seguinte, professor vitalício de Aritmética Elementar. Foi ainda revisor do Jornal de Aracaju e diretor do Banco de Sergipe, professor da cadeira Geometria e Álgebra em 1910, regendo a cadeira de Português a partir do ano de 1911 até sua morte (22/03/1918).

Continuando as investigações para identificar os professores do Atheneu Sergipense, de modo a estabelecer relações com a configuração das Matemáticas naquele estabelecimento de ensino, localizamos o senhor Abdias Bezerra, nascido em Siriri - SE, em 7 de setembro de 1880. Iniciou seus estudos secundários no Atheneu Sergipense, concluindo-os na Escola Militar do Realengo e, após concurso, preencheu a cadeira de Francês do Atheneu. Foi também professor das cadeiras de Aritmética e Álgebra, em 1911 e 1916; de Geometria e Trigonometria, em 1915; Matemática e Desenho, em 1933; e de Português, no ano de 1912. Com destacada atuação, assumiu as funções de Diretor do Atheneu Sergipense (1922) e Diretor da Instrução Pública do Estado de Sergipe (1923). Nesse cargo, viajou a São Paulo para observar os processos de ensino ali seguidos e tentar introduzi-los em Sergipe (Cf. GUARANÁ, 1925).

O farmacêutico Odilon de Oliveira Cardoso foi professor de Aritmética e Álgebra, em 1912, ao tempo em que o farmacêutico Antonio Batista Bittencourt lecionava Álgebra. Ensinando Geometria Descritiva (elementos e suas aplicações às sombras e perspectivas, principalmente gerais e práticas de agrimensura), em 1916, e Matemática, em 1930, o Atheneu Sergipense contou com o engenheiro paulista Gentil Tavares da Motta que, durante o período em que estudou no Atheneu, fundou e redigiu o jornal "O Necydalus", órgão defensor dos interesses dos estudantes. ${ }^{3}$ Sua veia jornalística fez as-

\footnotetext{
3 A respeito do jornal $O$ Necydalus, consultar Vidal (2009).
} 
sumir, no período de 1918 a 1922, a Imprensa Oficial do Estado de Sergipe, ocupando também o cargo de Diretor e Redator do Correio de Aracaju. Foi ainda Deputado Estadual e, em 1922, eleito para o mandato de Deputado Federal.

Cabe no momento dizer sobre o ato solene de colação de grau, ocorrido em 22 de março de 1911, do primeiro estudante a receber o Grau de Bacharel em Ciências e Letras do Atheneu Sergipense, Gentil Tavares da Motta. Notificada na imprensa local e assistida pelo "mundo intellectual aracajuano", a solenidade contou com a presença do Presidente do Estado, José Rodrigues da Costa Dórea; o Delegado Fiscal, Helvécio de Andrade; o Diretor do Atheneu, Candido Costa Pinto; e demais membros da Congregação do Atheneu Sergipense e da Escola Normal. O diplomado assumiu o seguinte compromisso: "Prometto, quanto em mim couber, concorrer para o adiantamento das lettras, cujo grao de Bacharel acaba de me ser conferido, e contribuir para o constante engrandecimento das lettras do Brazil" (Livro das Festividades do Atheneu Sergipense, 1908 a 1935). Aos intervalos dos discursos do jovem bacharel, que fez apologia ao sistema serial e ao curso de madureza, do paraninfo, o professor Brício Cardoso e do Presidente do Estado, ouviram-se músicas tocadas pelo batalhão da Polícia Militar, terminando a solenidade festiva com o Hino Sergipano. ${ }^{4}$

Era dever dos professores do Atheneu Sergipense cumprir o programa de ensino da sua cadeira, "o qual deverá ser limitado á doutrina exclusivamente util, san e substancial, evitando, no mais alto grao ostentação apparatosa de conhecimento", (Art. 135, Decreto 231 , de 9 de julho de 1897), sendo-lhes negado o direito de tratar de assuntos religiosos e políticos (Decreto 351, de 9 de junho de 1899). Os professores deviam ainda incentivar, nos exercícios, "os brios patrioticos de seus alumnos, afervorando-lhes cada vez mais o seu amor á patria”.
O corpo docente do Atheneu Sergipense pertencia a diferentes categorias. No Estatuto de 12 de janeiro de 1871, há a categoria de professor catedrático e professor substituto em exercício. Assim, lentes e professores formaram o quadro docente da instituição. Os professores ministrariam Desenho, e as demais cadeiras seriam lidas pelos lentes. Em 1921, os professores de Desenho e Ginástica podiam participar das reuniões da Congregação, quando os assuntos fossem referentes às suas aulas. No Decreto 721, de 31 de março de 1921, o professorado do Atheneu Sergipense estava composto de professores catedráticos, professores honorários e professores substitutos. Aparece aqui a figura do professor honorário, título conferido ao "homem de excepcional competencia eleito expontaneamente pelo voto de dous terços da totalidade da Congregação, podendo a investidura cahir a nacionais e estrangeiros" (Art.157).

Outra categoria de professor aparece no Decreto 912, de 12 de dezembro de 1925: a figura do "docente livre", escolhido por concurso e nomeado por Portaria do diretor da instituição pelo prazo de dez anos, com possibilidade de renovação. É possível compreender, a partir das peças legislativas relativas aos estudos secundários em Sergipe, as categorias de professores, bem como examinando outros tipos de documentação, verificar a forma de ingresso no magistério e as exigências requeridas. Estava dispensado dos concursos, pelo voto de dois terços da Congregação, o autor de "obra verdadeiramente notavel sobre o assunto da materia em questão" (Art.159, Decreto 633, de 17 de junho de 1916).

As investigações apontam ainda, no quadro docente do Atheneu Sergipense, o professor catedrático de Inglês Manoel Franco Freire que, em 1916, passa a lecionar Geometria e Trigonometria, tornando-se, a partir de 1924, catedrático da cadeira. Foi Diretor Geral da Instrução Pública (1927), Diretor da Escola Normal e Inspetor de Estabelecimentos Secundários do Estado de Sergipe (1931). São as diferentes fun-

\footnotetext{
${ }^{4}$ O número de alunos que concluiu o plano geral do curso e os estudos secundários era diminuto. No Imperial Colégio de Pedro II, por exemplo, estima-se que apenas 335 dos inúmeros matriculados, no período de 1838 a 1889, receberam o título de Bacharel em Letras (Cf. LORENZ, 2003, p.58).
} 
ções assumidas por professores do Atheneu Sergipense na sociedade, são "as relações estabelecidas com o exterior, com a cultura geral da sociedade" (Bittencourt, 2004, p.39).

Aberto concurso para a cadeira de Matemática do Atheneu Sergipense, em 23 de junho de 1929, inscreveram-se os candidatos João Alfredo Montes e Alfredo Guimarães Aranha, devendo em obediência a legislação, apresentar duas teses, uma voluntária e outra escrita sobre assunto sorteado pela Congregação. Cinqüenta era o número de exemplares exigidos a entregar nos concursos. Apesar dessa volumosa quantidade, localizei até o momento apenas um exemplar, o do candidato Alfredo Aranha. Indago: foi a ação do tempo ou dos homens que provocou tal silêncio, abafando as pesquisas?

O cidadão João Alfredo Montes, assume, após lograr êxito nesse concurso com média 5,19, a cadeira de Matemática no ano de 1930, exercendo também as funções de professor da cadeira de Física, em 1933.

O engenheiro civil, Alfredo Guimarães Aranha, em cumprimento à legislação, apresenta como tema de sua escolha, dissertação sobre "Potenciação e Radiciação", assim se expressando no prefácio do exemplar analisado:

O assumpto que servio de thema a este humillimo escripto é por demais conhecido, como bem poderá constatar a illustrada Commissão examinadora, cujo preparo scientifico é bem conhecido.

Sem o mais tenue vislumbre da vaidade, convencido, pelo contrario, dos poucos recursos da minha intelligencia e do minguado de conhecimentos, bem como da premencia de tempo, para apresentar um assumpto novo em mathematica, ainda assim, venho apresentar ao juizo da illustrada e douta Congregação deste Atheneu, o presente trabalho, de cujo julgamento espero a necessária clemencia (ARANHA, 1929, p. I).

Coube a Alfredo Aranha dissertar também sobre o ponto sorteado $\left(18^{\circ}\right)$ : "Fracções decimaes. Represen- tação graphica de funcções n'um sistema de coordenadas rectilineas. Esphera". O candidato coloca no texto de 135 páginas, parte da história, classificação e definição da ciência Matemática, prosseguindo de forma dissertativa sobre as temáticas estabelecidas.

Os professores mobilizam, em seu ofício, diferentes saberes, declara Monteiro em Bittencourt (2004). Mobilizou Aranha naquele texto o domínio do saber da disciplina, o saber de sua formação, o saber de sua experiência. O "saber docente" aprova Alfredo Aranha com média 6,68. Eleé nomeado docente livre da cadeira denominada Matemática no Atheneu Sergipense, no ano de 1930.

Daí para frente, outro momento se estabelece, tendo em vista que, por determinação legal, as Matemáticas (Aritmética, Álgebra, Geometria, Trigonometria) se unificam em um só ramo - Matemática.

\section{Considerações Finais}

Necessitava o "homem cientificamente preparado" universalizar seus conhecimentos e, nessa ampliação, a Aritmética, a Álgebra, a Geometria e a Trigonometria seriam necessárias. Saberes ministrados no Atheneu Sergipense que contou com a forte presença da figura do docente das Matemáticas.

Depreende-se, da análise da documentação, que os concursos transformavam-se em púlpitos para a demonstração intelectual dos candidatos. Ser docente no Atheneu Sergipense significava ser membro do circuito produtor dos modelos culturais, ser um dos agentes transmissores. Não só os primeiros foram mestres de destaque, outros beneméritos passaram pelo quadro docente do Atheneu Sergipense, conferindo, em duplo sentido, um status de prestígio intelectual e político.

Por tal processo, passaram sujeitos com diferentes formações: farmacêuticos, médicos, bacharéis, engenheiros, cirurgiões, dentistas, destacando o professor Eutychio de Novaes, que tinha o curso Normal. Os lentes do Atheneu Sergipense se faziam presentes em constantes artigos publicados na imprensa local, disseminando suas idéias, tornando-se visíveis na sociedade. Ao assumirem funções fora daquela casa, em diferentes circuitos culturais, extrapolavam os limites da instituição com estraté- 
gias de intervenção na sociedade, tomando assento em cargos legislativos, dirigindo órgãos públicos e políticos. Atuaram criticamente nas decisões da legislação educacional, emitiam pareceres ao serem solicitados pelo governo, ou ainda exigindo modificações no Regulamento da Instrução Pública do Estado de Sergipe (Cf. Ata da Congregação de 01/03/1915), dentre outras inserções.

A pesquisa "Professores de Matemática do Atheneu Sergipense" está concluída. Contudo, ao chegar a essa constatação, sinto ser invadida por dupla sensação: de dever cumprido e de dever inacabado. Ora, a primeira é observada ao conferir os objetivos traçados e, item a item, constatar a sua execução. Entretanto, a sensação do inacabado emerge também dos objetivos iniciais da pesquisa, planejados a priori, os quais, como sabemos, podem ser aprofundados e ampliados. A análise não se esgota, ainda há elementos a investigar, como por exemplo, levantar as teses apresen- tadas nos concursos e, por meio delas, examinar a história das diferentes disciplinas escolares, não só no processo ocorrido internamente em cada uma delas (Cf. PESSANHA, 2004), mas possibilitando compreender a cultura escolar.

Por certo, a configuração do saber matemático na escola secundária ocorreu provocada pelo envolvimento de múltiplos sujeitos: aqueles que defendiam, mesmo no anonimato, suas posições; os legisladores, ao elaborarem os projetos de Leis; a direção da instituição, ao exigir a execução da legislação; os professores, ao ministrarem suas aulas, conforme posições e práticas defendidas; e o próprio corpo discente, que se submetia às exigências dos demais. Cada um desses agentes, bem como o conjunto deles, em suas posições, funções e deveres, contribuíram de forma singular para revelar a configuração da disciplina escolar Matemática na instituição Atheneu Sergipense. 


\section{Referências}

\section{Bibliografia}

ALVES, Eva Maria Siqueira. O Atheneu Sergipense: uma Casa de Educação Literária examinada segundo os Planos de Estudos (1870-1908). Tese de Doutorado, PUC/SP, 2005.

ARANHA, Alfredo Guimarães. These apresentada ao Atheneu Pedro II pelo concurrente ao lugar de cathedratico secção de Mathematica. Bahia: Livreiro Editor, 1929.

BITTENCOURT, Circe Maria Fernandes. Ensino de História: fundamentos e métodos. São Paulo: Cortez, 2004.

CAMPOS, Edilberto. Crônicas da Passagem do século. 1968.

CHERVEL, André. "História das disciplinas escolares: reflexões sobre um campo de pesquisa”. In: Teoria \&Educação, 2, p. 177 - 229, 1990.

GOODSON, Ivor. Historia del curriculum la construcción social de lãs disciplinas escolares. Barcelona: Edciones Pomares-Corredor, 1998.

GUARANÁ, Armindo. Diccionario Bio-bibliográfico Sergipano. Rio de Janeiro, 1925.

LORENZ, Karl Michael. "O ensino de ciências e o Imperial Colégio Pedro II: 1838-1889”. In: VECHIA, Ariclê e CAVAZOTTI, Maria Auxiliadora (orgs.). A escola secundária - Modelos e Planos (Brasil, séculos XIX e XX). São Paulo: Annablume, 2003.

MORSE, Richard M. Formação histórica de São Paulo (de comunidade à metrópole). São Paulo: Corpo e Alma do Brasil, Difusão Européia do Livro, 1970 .
NÓVOA, Antônio. "Para o estudo sócio-histórico da gênese e desenvolvimento da profissão docente". In: Teoria \& Educação, Porto Alegre: n.4, 1991.

PEDRO II, Dom. "Diário do Imperador". In: Revista do IHGS, v.21, n.26b, 1965.

PESSANHA, Eurize Caldas, DANIEL, Maria Emília Borges, Menegazzo, Maria Adélia. "Da história das disciplinas escolares à história da cultura escolar: uma trajetória de pesquisa". In: Revista Brasileira de Educação, n.27, 2004.

VIDAL, Valdevania Freitas dos Santos. O Necydalus: um jornal estudantil do Atheneu Sergipense (19091911). Dissertação de Mestrado do NPGED/UFS, 2009.

\section{Fontes Manuscritas}

Livro das Correspondências do Lyceu de São Crsitóvão (1848 a 1851)

Atas da Congregação do Atheneu Sergipense (1871 a 1916)

Livro de Festividades (1908 a 1935)

Nomeação de Professores, Diretores e Outros Cargos (1904 a 1940)

Inscrição de concorrentes aos concursos (1909 a 1947)

\section{Legislação}

Regulamento Orgânico da Instrução Pública da Província de Sergipe, 24 de outubro de 1870.

Estatuto do Atheneu Sergipense, 12 de janeiro de 1871. Resolução 968, de 21 de abril de 1874.

Regulamento de 20 de abril de 1875.

Decreto 231, de 9 de julho de 1897.

Decreto 351, de 9 de junho de 1899.

Decreto 633, de 17 de junho de 1916.

Decreto 721, de 31 de março de 1921.

Decreto 912, de 12 de junho de 1925.

\section{Sobre a autora}

Eva Maria Siqueira Alves é Doutora em Educação pela Pontifícia Universidade Católica de São Paulo, Mestre em Educação e Licenciada em Matemática pela Universidade Federal de Sergipe, Professora do Departamento de Educação e do Mestrado e Doutorado em Educação da UFS, líder do Grupo de Pesquisa Disciplinas Escolares: História, Ensino, Aprendizagem (CNPq/UFS).

E-mail: evas@ufs.br 